\title{
Predictors of Satisfaction of Family Medicine Academy Trainers in Family Medicine Residency Training in Saudi Arabia
}

\author{
${ }^{1}$ Aminah Adil Al-Sulaiman, ${ }^{2 *}$ Nada Abdul-Rahman Al-Bunaian \\ ${ }^{1,2}$ Family Medicine Academy, Eastern Health Cluster, Saudi Arabia
}

\begin{abstract}
Keywords:

Satisfaction, Family Medicine,

Training, Trainers, Job

Received

14 February 2021

Received in revised form

14 March 2021

Accepted

16 March 2021

*Correspondence:

nada.bunaian@gmail.com

This study aims to identify the predictors of job satisfaction and perceived barriers of highquality training among Faculty Members in the Family Medicine Postgraduate Program. This study is a cross-sectional quantitative study with a sample size of 50 trainers in the Family Medicine Postgraduate training program in the Kingdom of Saudi Arabia. A validated survey was used, and the items' response categories were on the 5 Likert Scale. The data was collected through a web-based survey link, and focus group interviews were conducted to stress needs and recommendations. From 50 trainers, 32 have responded to the job satisfaction survey. Among them, $69.7 \%$ reported they were satisfied or very satisfied with their jobs $(9.1 \%$ and $60.6 \%$ reported being very satisfied and satisfied, respectively). Of all the statistically significant Job satisfaction predictors, six were Trainers' rating of their Administrative Department, one was a health status variable, and two were among burnout rating. Job satisfaction is a Multi-Dimensional construct that includes stress and burnout variables and depends on the trainers' perception of their work-life experience and environment. Although the job satisfaction among Family Medicine training was high, further efforts should be implemented to improve the job life and satisfaction by addressing multiple constructs.
\end{abstract}

Family Medicine (FM) is the foundation of medical practice worldwide. As the Kingdom of Saudi Arabia (KSA) is rapidly developing, FM is becoming the cornerstone of medical care (Aitken, AlSibaj, \& Al-Tamimi, 1988). The health care system development faces many challenges, such as rising birth rates, increased geriatrics proportion, and the escalating prevalence of the chronic disease. In KSA, Family physicians (FP) are needed now more than ever. The country needs to develop competent FP as leaders, teachers, and researchers are desperately needed in the health care system (Aitken et al., 1988). 
FP shortage in KSA was estimated to reach 15000 FP representing only $28 \%$ of the physician's power in primary health care centers (PHCC) (Family Medicine Academy Launching, Kingdom of Saudi Arabia, 2019). The lack of qualified physicians and the considerable expansion of the primary health care system around the Kingdom, reaching more than 2000 PHCC, indicates the need to focus on increasing FP. On top of that, the expansion of the community over the decades calls for a revolutionary restructuring in the healthcare system. Although many physicians apply for the family medicine postgraduate program (FMPGP) annually, there is a lack of adequate training centers, trainers, and resources. Accordingly, the Saudi Commission of health specialties (SCFHS) has increased the training capacity by more than five folds. As a result, these vast changes formed challenges for training this program which should be explored and appropriately addressed (AlKhaldi, Al-Ghamdi, Al-Mogbil, \& Al-Khashan, 2017; Khoja, 2015).

A Previous study revealed 95 centers training for SBFM around the kingdom covered by 241 trainers (Al-Khaldi et al., 2017). Based on that, it was recommended to increase the staff number and increase the policymakers' awareness about the importance of the FM Specialty. As a conclusion of that study, it was recommended to strengthen the government and system absorption of the requirement for the FM program, transform and restructure the design of the program and enhance community empowerment (Al-Khaldi et al., 2017). In 2019, the resources for training FPs were expanded. It was estimated that 2000 FPs need to graduate annually to meet the shortage, and only 300 are graduated annually in previous years (Al-Khathami, 2012). In response, under the authority of the ministry of health in the eastern province, the number of accredited training centers was increased to 17 training centers distributed in Al-Khobar, Dammam, and Qatif. It will further be increased annually to match training demands. In addition, 50 competent FPs Certified by the (SCFHS) were recruited for that purpose, and recruitment will further continue annually to match demands. Furthermore, in 2019, the curriculum was restructured to a three-year residency program focusing on developing highly competent FPs. It is a set goal to train $100 \mathrm{FP}$ each year to compensate for the shortage (Family Medicine Academy Launching, Kingdom of Saudi Arabia, 2019).

It is obvious now that there are enormous responsibilities for the academic FM trainers. These responsibilities include training postgraduate trainees, mentoring, providing clinical care, research, participation in quality improvement, and administration roles. It is a huge responsibility to deliver a high-quality service for their patients while fulfilling the training requirements (Krueger et al., 2017). For that reason, it is crucial to understand how these trainers perceive their environment and roles to attract, retain and nurture them for future leadership roles and continued excellence (Krueger et al., 2017).

Among many healthcare facilities, some give an example of coordinating the healthcare work while providing excellent training to the young generations. Yet, in other healthcare centers, the working and learning environments are less supportive, which causes an extra burden on the training doctors and trainees (GMC, 2017). Trainers and trainees' satisfaction surveys are conducted in many training facilities in the healthcare sector. In the UK, some healthcare facilities showed that almost one-quarter of their trainers are burnout and one-fifth of the trainees reported a high level of burnout (GMC, 2017).

The UK 2018 training satisfaction reviews showed that trainers enjoyed their role and all the benefits it provides. On the other hand, many doctors reported the pressure of the heavy work on 
them, working beyond their working hours, increased stress, and burnout. This will affect the quality of patient care, the trainers' wellbeing, and their trainees (Al-Khaldi et al., 2014).

The educational environment is an important measure of any educational process. In studies conducted in Saudi Arabia, it was revealed that among the training centers' challenges was the inadequate space for training, like small clinic rooms and inadequate supportive medical services. (Al-Khaldi et al., 2014; Al-Khathami, 2012). It was concluded that most centers that train FM do not support the training program, which causes conflicts in addition to the shortage of trainers. Furthermore, many trainers are loaded with unstable managerial and clinical loads (Al-Khaldi et al., 2014). They should have enough time in their job to meet their educational responsibilities and execute their role while meeting patient safety with a high quality of care (GMC, 2017). Little is known about further evaluating the predictors' satisfaction among Family Medicine trainers to support the trainers and the training environment. This study explores the predictors of job satisfaction and perceived barriers of high-quality training among Faculty Members in the Family Medicine Postgraduate program.

\section{Method}

All 50 trainers training residents in 17 centers distributed in Al-Khobar, Dammam, and Qatif cities were included in the study. The survey was administrated as a web-based Survey to all faculty members of the residency training and took 30 minutes to fill. The web survey was developed and validated in a similar study done by Kreuger (2017) in Canada. It was developed based on a literature review. Multiple meetings were conducted for refining questions and considering reliability, validity, and readability issues and avoiding the possibility of being offensive, leading, or biased. Then, the questionnaire was pretested with content experts, methodologists, and potential respondents. The questionnaire was revised and validated by some expert consultants from the residency training, and minor changes were made to apply to the residency training faculty. The final questionnaire explored demographics, practice settings, teaching, clinical settings, administration, research activities, past and present leadership roles, training needs and preferences, job satisfaction, health status, stress, and burnout. It also reviews trainers' perceptions about support, recognition, communication, retention, workload, teamwork, respect, resource distribution, remuneration, and infrastructure support. These questions' response categories were of a Likert scale from not at all important to very important. This survey was further supported by the Chief of residency training to ensure the highest response possible. Data were presented using descriptive statistics, then a bivariate (Chi-Square and Fisher's Exact) and multivariate analysis (logistic regression) were used to identify variables associated with job satisfaction. The IRB department approved the research of the residency training. Information of the subjects was kept confidential and was not used for any other purpose. A declaration was added to the survey heading that by participating in this survey the subject is consenting for his participation in this study.

\section{Results}

\section{Demographics}

Out of 50 Family Medicine trainers, 32 (64\%) trainers have responded. Fifty-six percent of participants reported working in the Family Medicine Academy (residency training) for less than a year, $15.6 \%$ reported working for one to two years, and the remaining worked for more than three years. 


\section{Bivariate Analysis}

Among the 32 participants, $69.7 \%$ were satisfied or very satisfied with their jobs. The survey included four domains: satisfaction towards the Local PHCC Administrative Department (LPAD), satisfaction towards the Residency Training Administrative Department (RTAD), their previous leadership roles, and level of burnout and job stress experienced. Of all the statistically significant Job satisfaction predictors, six were Trainers' rating of their RTAD, one was a health status variable, and two were among burnout rating.

Table 1 describes respondents' satisfaction with the LPAD. The LPAD was rated for teaching support, overall recognition for teaching efforts, communication, teamwork, resource distribution, respect, and clinic workload. No significant factors were found to be predictive of job satisfaction among the trainers. However, 37.5\% (12) rated LPAD support to be very good to excellent, $83.3 \%$ were satisfied in their job. Regarding communication, only seven among those who were satisfied thought that the communication of LAPD was excellent to very good. On the contrary, 16 were satisfied with their jobs yet rated communication as good, fair, or poor. Teamwork among staff and physicians in the PHCC was rated excellent to very good by $40.6 \%$ of participants, of which $76.9 \%$ (10) were satisfied with their jobs. Furthermore, only seven of satisfied participants rated the resources distribution to be very good and excellent. Moreover, half of participants (16) rated respect to be very good to excellent, of which $75 \%$ (12) were satisfied with their jobs. The workload was rated based on the workload experiences in the clinic and the ability to balance with family life. Of 31 participants, 13 thought workload to be very good to excellent of which $53.8 \%$ (7) were satisfied.

Table 1

Rating Potential Predictors of Job Satisfaction of Local PHCC Administrative Department

\begin{tabular}{|c|c|c|c|c|}
\hline & Overall Job Satisfaction & & Total & \\
\hline $\begin{array}{l}\text { Ratings of Potential Predictors Variables } \\
\text { (Local PHCC Administrative Department) }\end{array}$ & $\begin{array}{l}\text { Number of trainers } \\
\text { Very Satisfied and } \\
\text { Satisfied, (\% of } \\
\text { satisfied among } \\
\text { ratings of predictors } \\
\quad \text { variables) }\end{array}$ & Other Response, n (\%) & $\begin{array}{l}\text { Total (Ratings of potential } \\
\text { predictors) }\end{array}$ & P-Value \\
\hline \multicolumn{5}{|l|}{ Overall Support of Teaching $(n=32)$} \\
\hline Very good or Excellent & $10(83.3 \%)$ & $2(16.7 \%)$ & $12(37.5 \%)$ & .26 \\
\hline Good, Fair or Poor & $13(65 \%)$ & $7(35 \%)$ & $20(62.5 \%)$ & \\
\hline \multicolumn{5}{|l|}{ Overall Recognition of Teaching $(n=27)$} \\
\hline Very Good or Excellent & $5(100 \%)$ & $0(0 \%)$ & $5(18.5 \%)$ & .10 \\
\hline Good, Fair or Poor & $14(63.6 \%)$ & $8(36.4 \%)$ & $22(81.4 \%)$ & \\
\hline \multicolumn{5}{|l|}{ Communication $(n=32)$} \\
\hline Very Good or Excellent & $7(70 \%)$ & $3(30 \%)$ & $10(31.25 \%)$ & .87 \\
\hline Good, Fair or Poor & $16(72.7 \%)$ & $6(27.3 \%)$ & $22(68.75 \%)$ & \\
\hline \multicolumn{5}{|l|}{ Teamwork $(n=32)$} \\
\hline Very good or Excellent & $10(76.9 \%)$ & $3(23.1 \%)$ & $13(40.6 \%)$ & .55 \\
\hline Good, Fair or Poor & $13(68.4 \%)$ & $6(31.6 \%)$ & $19(59.37 \%)$ & \\
\hline \multicolumn{5}{|l|}{$\begin{array}{l}\text { Resource Distribution for clinic work, } \\
\text { Teaching and Information system }(n=32)\end{array}$} \\
\hline Very good or Excellent & $7(87.5 \%)$ & $1(12.5 \%)$ & $8(25 \%)$ & .25 \\
\hline Good, Fair or Good & $16(66.7 \%)$ & $8(33.3 \%)$ & $(75 \%)$ & \\
\hline \multicolumn{5}{|l|}{ Respect $(n=32)$} \\
\hline Very good or Excellent & $12(75 \%)$ & $4(25 \%)$ & $16(50 \%)$ & 69 \\
\hline Good, Fair or Poor & $11(68.8 \%)$ & $5(31.3 \%)$ & $16(50 \%)$ & \\
\hline \multicolumn{5}{|l|}{ The workload in the clinic $(n=31)$} \\
\hline Very good or Excellent & $7(53.8 \%)$ & $6(46.2 \%)$ & $13(41.9 \%)$ & .06 \\
\hline Good, Fair or Poor & $16(84.2 \%)$ & $3(15.8 \%)$ & $19(61.2 \%)$ & \\
\hline
\end{tabular}




\section{Rating RTAD}

Table 2 demonstrates the rating of the RTAD. It was surveyed for overall support for teaching, research, mentoring, leadership, recognition of teaching, communication, teamwork, resource distribution, quality of leadership in administration, the workload in the clinic, control over teaching environment, and respect. From the predictors surveyed among RTAD, six had a significant statistical association. The factors were recognition for teaching efforts, open and honest communication, the leadership of the administration and academic coordinators, reasonable workload, control over the teaching environment, and respect.

Rating the RTAD for support for teaching, leadership, research, and mentoring, most trainers $81.25 \%$ (26) rated as very good to excellent, of which $76.9 \%$ (20) were satisfied. Furthermore, recognition of teaching was rated very good to excellent by almost two-thirds $(67.7 \%)$, of which $85.7 \%$ (18) were satisfied with their jobs.

Teamwork was evaluated among leadership, coordinators, and trainers. Almost two-thirds, $62.5 \%$ (20) rated teamwork to be very good to excellent, of which $80 \%$ (16) were satisfied. Forty percent of participants thought that resource distribution for clinic and teaching was very good to excellent, of which $76.9 \%$ (10) were satisfied.

RATD leadership was rated for quality of leadership among Chief of the Academy and Committees leaders. Of 32 participants, 25 (78.1\%) thought leadership was very good to excellent, of which $84 \%$ (21) were satisfied. Out of 32 participants, 30 responded to rating workload. Approximately $45.1 \%$ of them rated workload to be very good to excellent, and all of them were satisfied with their jobs. Among 32 participants, 29 (90.6\%) thought that respect was very good to excellent, of which $79.3 \%$ (23) were satisfied.

Table 2

Potential Predictors of Job Satisfaction of Family Medicine Academy Trainers of Administrative Department

\begin{tabular}{|c|c|c|c|c|}
\hline \multicolumn{5}{|c|}{ Overall Job Satisfaction } \\
\hline $\begin{array}{l}\text { Potential Predictors Variables (Family Medicine Academy } \\
\text { Administrative Department) }\end{array}$ & $\begin{array}{c}\text { Very Satisfied } \\
\text { and Satisfied, N } \\
(\%)\end{array}$ & $\begin{array}{c}\text { Other } \\
\text { Response, } \\
\text { N (\%) }\end{array}$ & $\begin{array}{c}\text { Total (Ratings } \\
\text { of potential } \\
\text { predictors) }\end{array}$ & $\begin{array}{c}\text { P- } \\
\text { Value }\end{array}$ \\
\hline \multicolumn{5}{|c|}{ Overall Support of Teaching, Research, Leadership, Mentoring and Career $(\mathbf{n}=32)$} \\
\hline Very good or Excellent & $20(76.9 \%)$ & $6(23.1 \%)$ & $26(81.25 \%)$ & .24 \\
\hline Good, Fair or Poor & $3(50 \%)$ & $3(50 \%)$ & $6(18.75 \%)$ & \\
\hline \multicolumn{5}{|l|}{ Overall Recognition of Teaching efforts $(n=31)$} \\
\hline Very Good or Excellent & $18(85.7 \%)$ & $3(14.3 \%)$ & $21(67.7 \%)$ & .03 \\
\hline Good, Fair or Poor & $5(50 \%)$ & $5(50 \%)$ & $10(32.2 \%)$ & \\
\hline \multicolumn{5}{|c|}{ Communication (open and honest communication in Administrative Department $(n=31)$} \\
\hline Very Good or Excellent & $18(85.7 \%)$ & $3(15 \%)$ & $20(64.5 \%)$ & .02 \\
\hline Good, Fair or Poor & $5(45.5 \%)$ & $6(54.5 \%)$ & $11(35.4 \%)$ & \\
\hline \multicolumn{5}{|c|}{ Communication (Transmitting information Administration) $(n=31)$} \\
\hline Very good or Excellent & $14(77.8 \%)$ & $4(22.2 \%)$ & $18(58 \%)$ & .32 \\
\hline Good, Fair or Poor & $8(61.5 \%)$ & $5(38.5 \%)$ & $13(41.9 \%)$ & \\
\hline \multicolumn{5}{|l|}{ Teamwork $(n=32)$} \\
\hline Very good or Excellent & $16(80 \%)$ & $4(20 \%)$ & $20(62.5 \%)$ & .18 \\
\hline Good, Fair or Poor & $7(58.3 \%)$ & $5(41.7 \%)$ & $12(37.5 \%)$ & \\
\hline \multicolumn{5}{|l|}{ Resource Distribution for Teaching and Clinics $(n=32)$} \\
\hline Very good or Excellent & $10(76.9 \%)$ & $3(23.1 \%)$ & $13(40.6 \%)$ & .59 \\
\hline Good, Fair or Good & $13(68.4 \%)$ & $6(31.6 \%)$ & $19(59.3 \%)$ & \\
\hline \multicolumn{5}{|l|}{ Quality of Administration and Academic leadership $(n=32)$} \\
\hline Very good or Excellent & $21(84 \%)$ & $4(16 \%)$ & $25(78.1 \%)$ & .01 \\
\hline Good, Fair or Poor & $2(28.6 \%)$ & $5(71.4 \%)$ & $7(21.8 \%)$ & \\
\hline \multicolumn{5}{|l|}{ Workload (reasonable workload) $(\mathrm{n}=\mathbf{3 0})$} \\
\hline Very good or Excellent & $13(100 \%)$ & $0(0 \%)$ & $13(43.3 \%)$ & .00 \\
\hline Good, Fair or Poor & $9(52.9 \%)$ & $8(47.1 \%)$ & $17(56.6 \%)$ & \\
\hline \multicolumn{5}{|l|}{ Workload (Control over teaching environment) $(n=31)$} \\
\hline Very good or Excellent & $14(100 \%)$ & $0(0 \%)$ & $14(45.1 \%)$ & .00 \\
\hline Good, Fair or Poor & $8(47.1 \%)$ & $9(52.9 \%)$ & $17(54.8 \%)$ & \\
\hline \multicolumn{5}{|l|}{ Respect $(n=32)$} \\
\hline Very good, Excellent & $23(79.3 \%)$ & $6(20.7 \%)$ & $29(90.6 \%)$ & .00 \\
\hline Good, Fair or Poor & $0(0 \%)$ & $3(100 \%)$ & $3(9.3 \%)$ & \\
\hline
\end{tabular}




\section{Health Status and Stress}

As shown in Table 3, participants were surveyed for their previous roles in leadership in the past. Among 32 participants, 59.3\% (19) of them had previous leadership roles. Among them, 68.4\% (13) were satisfied. On the other hand, satisfaction reached $76.9 \%$ of participants that had no previous leadership.

The third part of the survey addressed burnout among trainers. Using the Maslach burnout inventory scale, emotional exhaustion had a mean score of 30.59 (8.25) among satisfied trainers, while among the others, it was 46.8 (12.17). Regarding depersonalization, among satisfied trainers, the mean score was 8.7 (3.82) and 13.42 (6.18\%) among others. Both emotional exhaustion and depersonalization scores had a significant association with satisfaction. On the other hand, personal achievement had a mean score of 46.31 (5.54) among satisfied trainers and 44.85 (8.76) among others but had no statistical significance.

Regarding health status and level of stress, among 32 participants, 53.1\% (17) rated their health to be very good to excellent, of which $70.6 \%$ (12) were satisfied. On the contrary, $73.3 \%$ (11) chose the ratings "Poor, Fair or Good." Regarding the level of stress, 3.12\% (7) rated training to be quite or extremely stressful while $78.1 \%$ (25) thought it was not at all, not very or a bit stressful. Of those who thought it was quite or extremely stressful, only $28.6 \%$ (2) were satisfied, in contrast to $84 \%$ who selected "not at all, not very or a bit."

Table 3

Potential Predictors of Job Satisfaction Rating Burnout, Health Status, and Stress among Family Medicine Academy Trainers

\begin{tabular}{|c|c|c|c|c|}
\hline \multirow[b]{2}{*}{$\begin{array}{l}\text { Potential Predictors Variables (Family Medicine Academy Administrative } \\
\text { Department) }\end{array}$} & \multicolumn{2}{|c|}{ Overall Job Satisfaction } & \multirow[b]{2}{*}{$\begin{array}{c}\text { Total } \\
\text { (Ratings of } \\
\text { potential } \\
\text { predictors) }\end{array}$} & \multirow[b]{2}{*}{ P-Value } \\
\hline & $\begin{array}{c}\text { Very Satisfied } \\
\text { and Satisfied, } \\
\qquad \mathrm{N}(\%)\end{array}$ & $\begin{array}{l}\text { Other Response, } \\
\qquad \mathrm{N}(\%)\end{array}$ & & \\
\hline \multicolumn{5}{|l|}{ Maslach Burnout Inventory rating for emotional exhaustion $(\mathrm{n}=29)$} \\
\hline Mean $(\mathrm{SD})$ Score & $30.59(8.25)$ & $46.8(12.17)$ & 29 & .01 \\
\hline Number & 22 & 7 & & \\
\hline \multicolumn{5}{|l|}{ Maslach Burnout Inventory rating for depersonalization $(n=28)$} \\
\hline Mean (SD) Score & $8.7(3.82)$ & $13.42(6.18)$ & 28 & .02 \\
\hline Number & 21 & 7 & & \\
\hline \multicolumn{5}{|l|}{ Maslach Burnout Inventory rating for low personal Achievements $(n=29)$} \\
\hline Mean (SD) Score & $46.31(5.54)$ & $44.85(8.76)$ & 29 & 60 \\
\hline Number & 22 & 7 & & \\
\hline \multicolumn{5}{|l|}{ Leadership role in the past $(n=32)$} \\
\hline Yes & $13(68.4 \%)$ & $6(31.6 \%)$ & $19(59.3 \%)$ & .59 \\
\hline No & $10(76.9 \%)$ & $3(23.1 \%)$ & $13(40.6 \%)$ & \\
\hline \multicolumn{5}{|l|}{ Health status $(\mathrm{n}=32)$} \\
\hline Very good or Excellent & $12(70.6 \%)$ & $5(29.4 \%)$ & $17(53.1 \%)$ & .86 \\
\hline Poor, Fair or Good & $11(73.3 \%)$ & $4(26.7 \%)$ & $15(46.8 \%)$ & \\
\hline \multicolumn{5}{|l|}{ Stress $(n=32)$} \\
\hline Quite or extremely stressful & $2(28.6 \%)$ & $5(71.4 \%)$ & $7(3.12 \%)$ & .00 \\
\hline Not at all, not very or a bit & $21(84 \%)$ & $4(16 \%)$ & $25(78.12 \%)$ & \\
\hline
\end{tabular}

\section{Demographic Factors}

As presented in Table 4, among 32 participants, 30\% provided their gender and marital status. Out of 9 males, 55.6\% were satisfied, and among 21 females, $81 \%$ were satisfied. On the other hand, all single trainers $100 \%$ (3) were satisfied in contrast to $19(70.4 \%)$ of married trainers. 
Table 4

Potential Demographic Predictors of Job Satisfaction among Family Medicine Academy Trainers

\begin{tabular}{|c|c|c|c|c|}
\hline Potential demographic predictor variable & $\begin{array}{c}\text { Very Satisfied and } \\
\text { Satisfied, N(\%) } \\
\end{array}$ & $\begin{array}{c}\text { Other Response, } \\
\mathrm{N}(\%) \\
\end{array}$ & Total & P-Value \\
\hline \multicolumn{5}{|l|}{ Gender $(n=30)$} \\
\hline Male & $5(55.6 \%)$ & $4(44.4 \%)$ & $9(30 \%)$ & .15 \\
\hline Female & $17(81 \%)$ & $4(19 \%)$ & $21(70 \%)$ & \\
\hline \multicolumn{5}{|l|}{ Marital Status $(n=30)$} \\
\hline Single & $3(100 \%)$ & $0(0 \%)$ & $3(10 \%)$ & .15 \\
\hline Married & $19(70.4 \%)$ & $8(29.6 \%)$ & $27(90 \%)$ & \\
\hline
\end{tabular}

\section{Multivariate Analysis}

The final adjusted logistic regression model contained five job satisfaction predictors: recognition $(\mathrm{OR}=.17,95 \% \mathrm{CI} .006$ to 5.30$)$, Communication (OR $=.13,95 \% \mathrm{CI} .005$ to 3.56) and Leadership quality (OR $=.19,95 \% \mathrm{CI} .007$ to 5.57 ) among RATD, stress experienced by trainers (OR = 11.56, $95 \%$ CI .33 to 92$)$ and having higher emotional exhaustion burnout subscale (OR $=1.18,95 \%$ CI .94 to 1.48$)$.

Table 5

Final Multivariate Logistic Regression Model of Predictors of Satisfaction Among Family Medicine Academy Trainers

\begin{tabular}{lc}
\hline Predictors of Job Satisfaction & Adjusted ODDS RATIO (95\% CI) \\
\hline Maslach Burnout Inventor emotional exhaustion subscale & $1.182(.94-1.48)$ \\
Recognition of Family Medicine Academy & $.179(.006-5.30)$ \\
Communication & $.137(.005-3.56)$ \\
leadership & $.193(.007-5.56)$ \\
Stress & $11.56(.33-92.9)$ \\
\hline Hosmer-Lemeshow goodness-of-fit-test $=.60$ & \\
Naglekerke $\mathrm{R}^{2}=.70$ & \\
Cox Snell $\mathrm{R}^{2}=.47$ & \\
\hline Note. $\mathrm{N}=28$ (Of the 32 participants, $4(12.5 \%)$ had missing values for one or more variables included in the final model.
\end{tabular}

\section{Discussion}

As with any other study of stress or satisfaction, it is almost impossible to know if participants are giving their genuine opinion about their job duties as some participants might play down the negative aspects of their career to deny their inability to cope, or they might exaggerate their negative thoughts to gain some improvements. But comparing different factors for stress and satisfaction might help eliminate those types of bias (Chambers, Wall, \& Campbell, 1996). Furthermore, any educational institute's academic success depends on the training faculty in terms of how well they teach, quality of patient service, and contribution. On the other hand, it was shown that medical educational careers are endangered by the lack of teaching time, self-development, and professional renewal (Lowenstein, Fernandez, \& Crane, 2007). Also, job satisfaction was linked to patient satisfaction and the quality of service they received. Based on that, any medical education institute should pay attention to any training faculty discontent (Lowenstein et al., 2007).

\section{Local PHCC Administrative Department (LAPD)}

In literature, the lack of support from department administration and overlooking the education faculty efforts was a significant predictor of job satisfaction (Lowenstein et al., 2007). Some thought the department administration is not providing adequate facilities to provide the best quality of training. Additionally, comparing the educational career of medical educators and scientists, it was revealed that medical educators receive less feedback and mentoring from the department, lower promotion rates, and lower levels of career satisfaction (Lowenstein et al., 2007). Among 
Family Medicine Postgraduate Trainers, there was no significant association between job satisfaction and LAPD factors. However, most trainers rated their support and recognition as poor, fair, or good. Furthermore, Communication with LAPD had no significant association with job satisfaction, although almost two-thirds of trainers rated it as poor, fair, or good. This could be explained by the fact that trainers consider the residency training as their administrative department and do not expect much of LAPD. Furthermore, among PHCC in the Eastern Province, some are familiar with the training culture of the Family Medicine Program, yet others are newly accredited for training. The staff in PHCCs are adapting to the teaching culture practice in their centers, and the administration of the LAPD is cooperating more than before to support training.

Regarding teamwork, literature elaborated its linkage to job satisfaction (Lowenstein et al., 2007). Similarly, resource distribution was associated with satisfaction as it raises the quality of teaching and performance satisfaction (Lowenstein et al., 2007). In this study, resource distribution and teamwork were not significantly associated with trainers' satisfaction, although resource availability varies from one sector to another. This might be justified because trainers coped to the level of teamwork and resource distribution in their centers long before they joined the training career. So, it did not have a major effect on their satisfaction with their jobs, but it might cause moderate dissatisfaction when it comes to training duties. Furthermore, teamwork might vary among different centers and could depend on the PHCC staff cooperation and the trainers' attitude.

Clinic workload and balance with family life were one of the strongest predictors associated with job satisfaction in previous studies. As a training career requires huge efforts to meet training requirements, literature revealed its effect on balance with family life. With time, they become less willing to sacrifice family life for their career's sake (Lowenstein et al., 2007). In this study, this factor was not significant concerning clinic workload, although most rated it as poor, fair, or good. To Justify this, it might be because clinic workload is fixed with fixed duty hours, which will not affect family life. However, training takes extra effort in the clinic, but this was balanced with limited number of patients seen per clinic to reach 10 patients maximum per 4 hours clinic coping with training requirements in addition to assigning each trainer to 6-8 clinics workload per week in contrast to 10 clinics per week of non-training physicians.

\section{RTAD}

Among predictors of satisfaction for the RTAD, six were significantly associated with job satisfaction. The fact that more factors were associated significantly with satisfaction towards RTAD than LPAD might be explained by the possibility of trainers' feelings that they belong more to the RTAD. Most trainers rated the RTAD to be excellent to very good regarding support and recognition. Recognition for these efforts had a significant association with their satisfaction. Furthermore, studies done to evaluate the effect of communication between the department and their faculty on their job satisfaction revealed that it is a significant effect as it contributes to their sense of worthiness and their perception of institutional equity (Bunton et al., 2012). In this study, communication with the RTAD showed significant association where most trainers thought they received open and honest communication with perceived department transparency. Regarding teamwork, not much was published in literature regarding the association between teamwork and satisfaction among academic faculty. However, studies among nursing staff reveal that teamwork provides higher levels of satisfaction (Krueger et al., 2017). In this study, it was not significantly associated with satisfaction, which might be explained by the fact that trainers in residency training 
do not contact on a daily basis with other teaching faculty as they attend the Academy once per week in out of clinic duty on different days.

In literature, department leadership was among the important predictors of job satisfaction (Bunton et al., 2012). In this study, results confirm this as it had a significant association, and most trainers rated the quality of leadership to be very good to excellent. This indicated that the leaders have a predictable role in increasing the satisfaction of the training faculty.

This study confirms previous literature results regarding workload, balance with life, and control over a work environment as it was a significant predictor in this study (Bunton et al., 2012). Trainers who think they have excellent to very good workload with an acceptable family balance level were more satisfied. The training duties were distributed between trainers in a balanced manner by the leadership administration. Among other significant predictors of job satisfaction was respect practice in the environment from leadership and colleagues.

\section{Health Status and Stress}

Health Status had no significant association with job satisfaction in this study. On the other hand, stress had a significant association as most trainers rated their job stress to be not at all, not very, or a bit stressful. The more trainers perceived that their job was not stressful, the more they were satisfied. Regarding burnout scale, emotional exhaustion and depersonalization subscales had statistical significance to satisfaction compared to the low personal achievement subscale. The emotional exhaustion subscale reflects the stress burnout dimension. This indicates that trainers who experienced higher levels of exhaustion from their work are less likely to be satisfied, which further supports the literature.

\section{Demographic Factors}

Regarding demographic factors, gender and marital status had no significant association. Most females were satisfied with their jobs in contrast to the satisfaction of almost only half of males. On the other hand, all single trainers were satisfied, and about two-thirds of married training faculty were satisfied, which might reveal the element of balance with family life.

\section{Conclusion}

Job satisfaction is a multi-dimensional construct that includes stress and burnout variables and the perception of the training faculty of their work-life experience and environment (leadership, communication, recognition). Although the job satisfaction among residency trainers was high, further efforts should be implemented to improve the job life and satisfaction among trainers by addressing multiple constructs.

Among this study's strengths is that the comprehensive questionnaire was based on previous research, with rigorous pretesting and pilot testing in the research that developed this questionnaire. Many limitations exist in this study as the response rate was $64 \%$ of the faculty. Previous similar studies had a similar response rate ranging from 30\% to 65\% (Bunton et al., 2012). The number of training faculty in the residency training was only 50 trainers that lead to the fact that the sample size was small. Furthermore, the study was conducted in a single department. However, the findings appear to agree with published literature findings and might be of value and relevance to other studies of job satisfaction on similar populations. 


\section{References}

Aitken, A. M., Al-Sibaj, M. H., \& Al-Tamimi, T. M. (1988). The king faisal university fellowship training programme in family and community medicine. Family Practice, 5(4), 253-259. https://doi.org/10.1093/fampra/5.4.253

Al-Khaldi, Y., Al-Meqbel, T., Al-Shmmari, S., Al-Yahya, O., AlBar, A., AlDawood, K., ... Al-Ghamdi, M. (2014). Challenges facing postgraduate training in family medicine in Saudi Arabia: Patterns and solutions. Journal of Health Specialties, $2(2), 61$. https://doi.org/10.4103/1658-600x.131752

Al-Khaldi, Y. M., Al-Ghamdi, E. A., Al-Mogbil, T. I., \& Al-Khashan, H. I. (2017). Family medicine practice in Saudi Arabia: The current situation and Proposed Strategic Directions Plan 2020No Title. Journal of Family and Community Medicine, 24(3). Retrieved from https://www.researchgate.net/publication/319370474_Family_medicine_practice_in_Saudi_Arabia_The_current_situation_an d_Proposed_Strategic_Directions_Plan_2020/link/5a219b3b4585155dd41aa934/download

Al-Khathami, A. D. (2012). Evaluation of Saudi family medicine training program: The application of CIPP evaluation format. Medical Teacher, 34(SUPPL. 1), 81-89. https://doi.org/10.3109/0142159X.2012.656752

Bunton, S. A., Corrice, A. M., Pollart, S. M., Novielli, K. D., Williams, V. N., Morrison, L. A., ... Fox, S. (2012). Predictors of workplace satisfaction for U.S. medical school faculty in an era of change and challenge. Academic Medicine, 87(5), 574-581. https://doi.org/10.1097/ACM.0b013e31824d2b37

Chambers, R., Wall, D., \& Campbell, I. (1996). Stresses, coping mechanisms and job satisfaction in general practitioner registrars. British Journal of General Practice, 46(407), 343-348. Retrieved from http://ovidsp.ovid.com/ovidweb.cgi?T=JS\&PAGE=reference \&D=emed4\&NEWS=N\&AN=1996202002

Family Medicine Academy Launching, Kingdom of Saudi Arabia. (2019, October 29). Alyaum. Retrieved from https://www.alyaum.com/articles/6218682/المملكة_اليوم/إطلاق_أكاديمية_طب_الأسرة-بالثرقية_الأكبر-بالمملكة/29

GMC. (2017). Training environments 2017: Key findings from the national training surveys. https://doi.org/2018

Khoja, A. T. (2015). Evaluation of the educational environment of the Saudi family medicine residency training program. Journal of Family and Community Medicine, 22(1), 49-56. https://doi.org/10.4103/2230-8229.149591

Krueger, P., White, D., Meaney, C., Kwong, J., Antao, V., \& Kim, F. (2017). Predictors of job satisfaction among academic family medicine faculty. Canadian Family Physician, 63(3), E177-E185.

Lowenstein, S. R., Fernandez, G., \& Crane, L. A. (2007). Medical school faculty discontent: Prevalence and predictors of intent to leave academic careers. BMC Medical Education, 7, 1-8. https://doi.org/10.1186/1472-6920-7-37 